
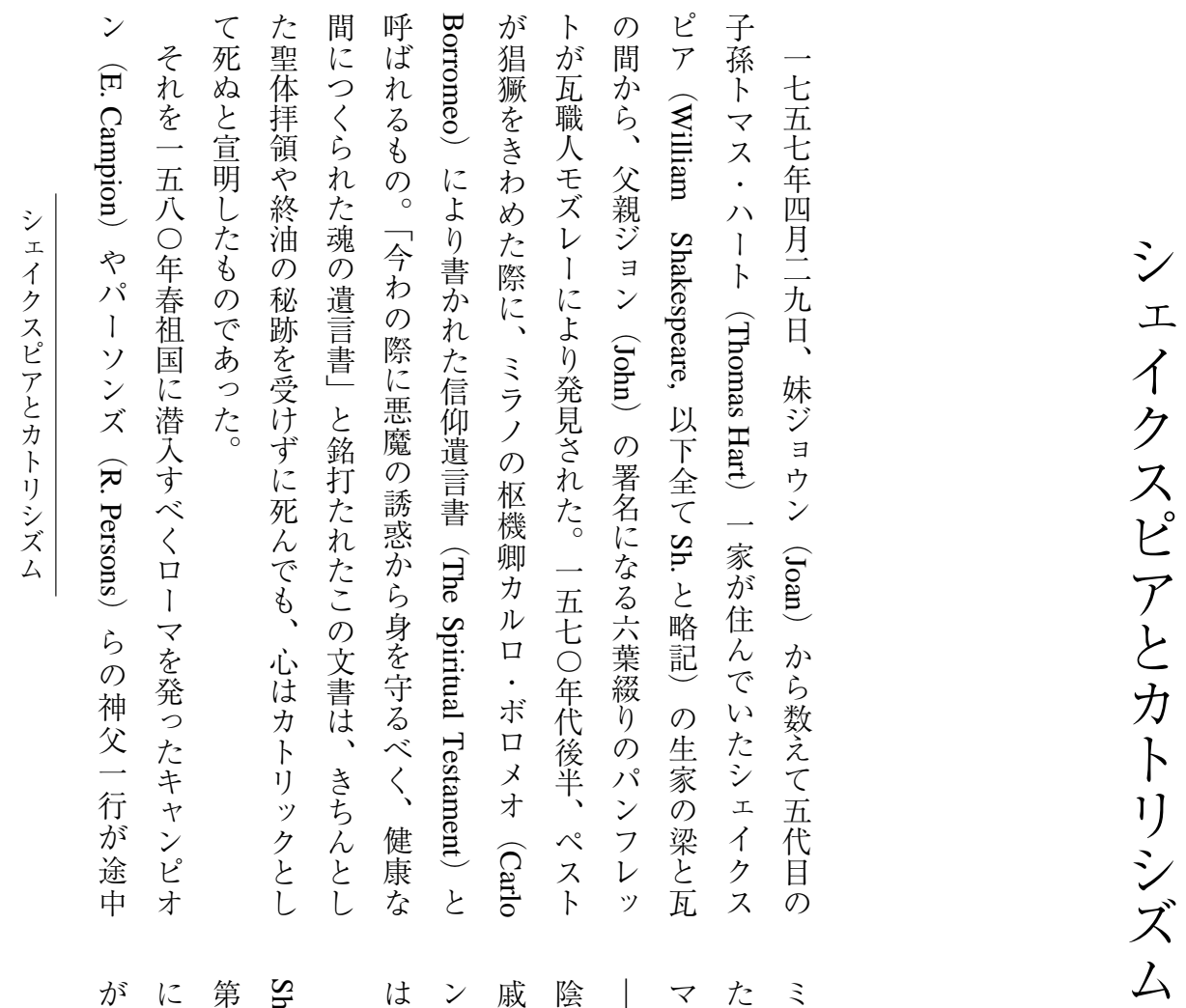

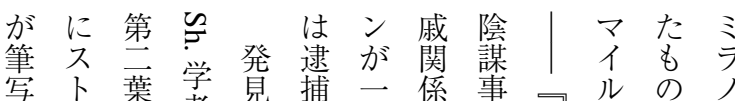

時ラ荣者見捕冊僁事件りほをへ

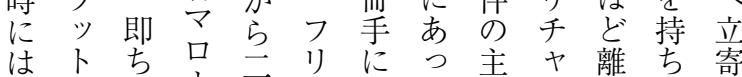

紛フ第! $\overrightarrow{0}$ । 入た犯! 犯帰哥

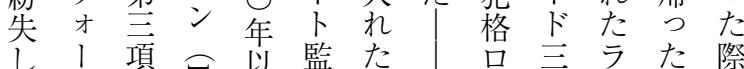

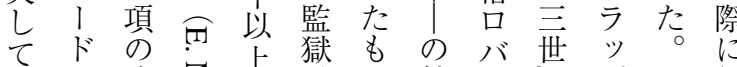

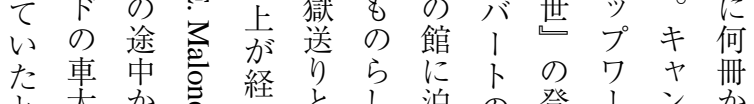

と大加経とし泊の登、ン学

少に第 の

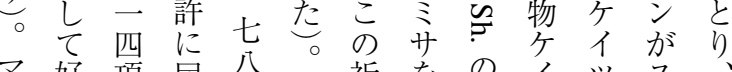

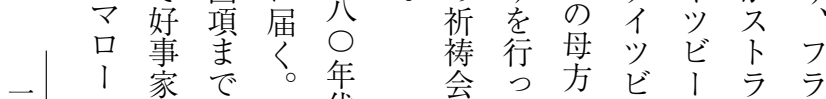

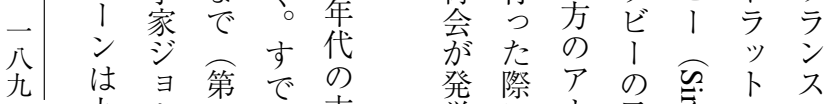

九 一に覚に亦子ほフの

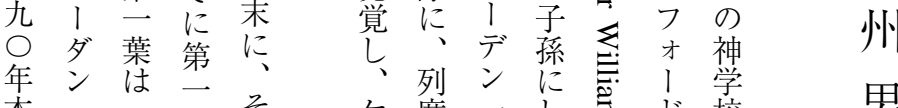

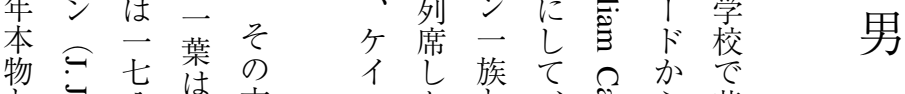

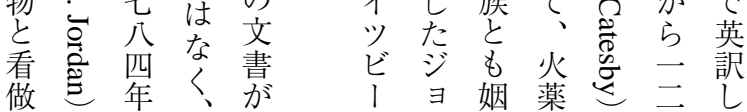




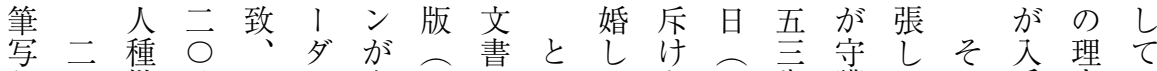

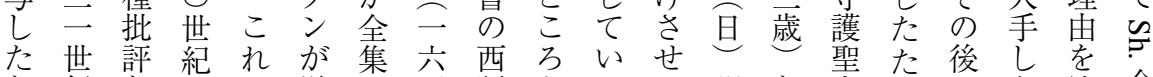
と紀と最で送に言語がるて誕と聖た後た述全

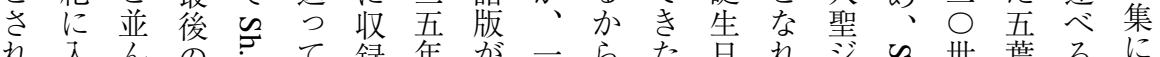

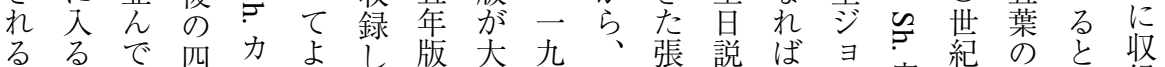

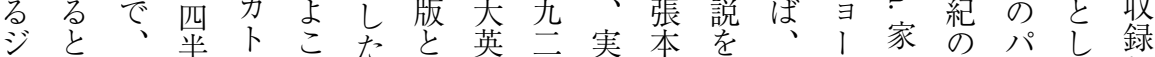

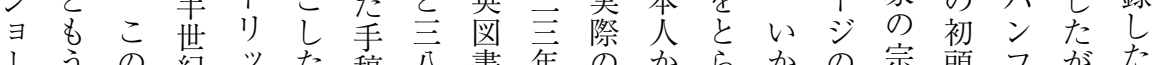

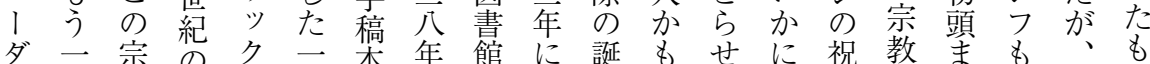

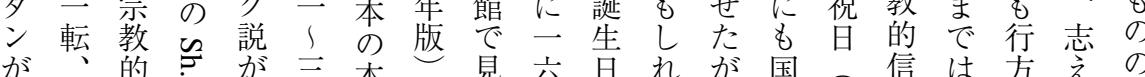

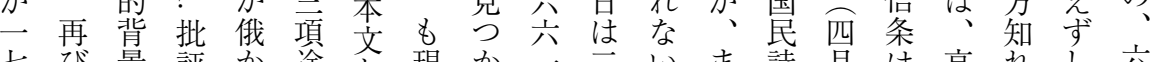

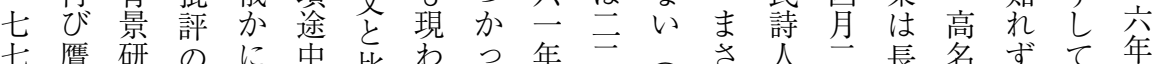
○作究賑脚ま較れたに百な令主長名ずて、後 了説がわ光で検る。メだ拉こ名亘間气低一に 巻

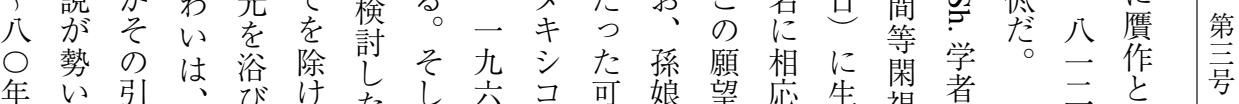

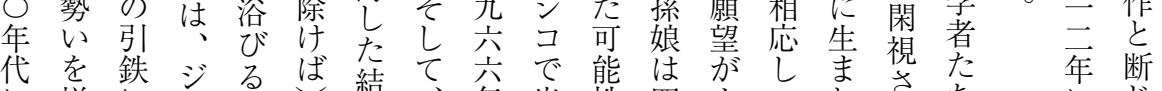

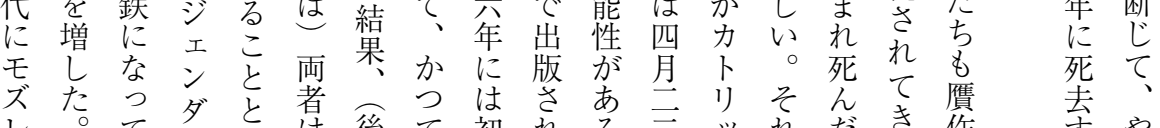

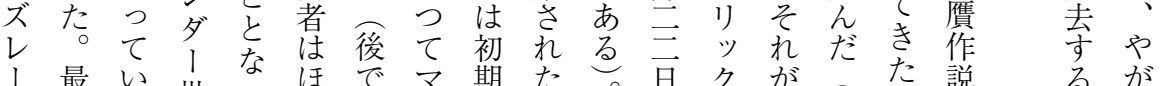
を最い批っ

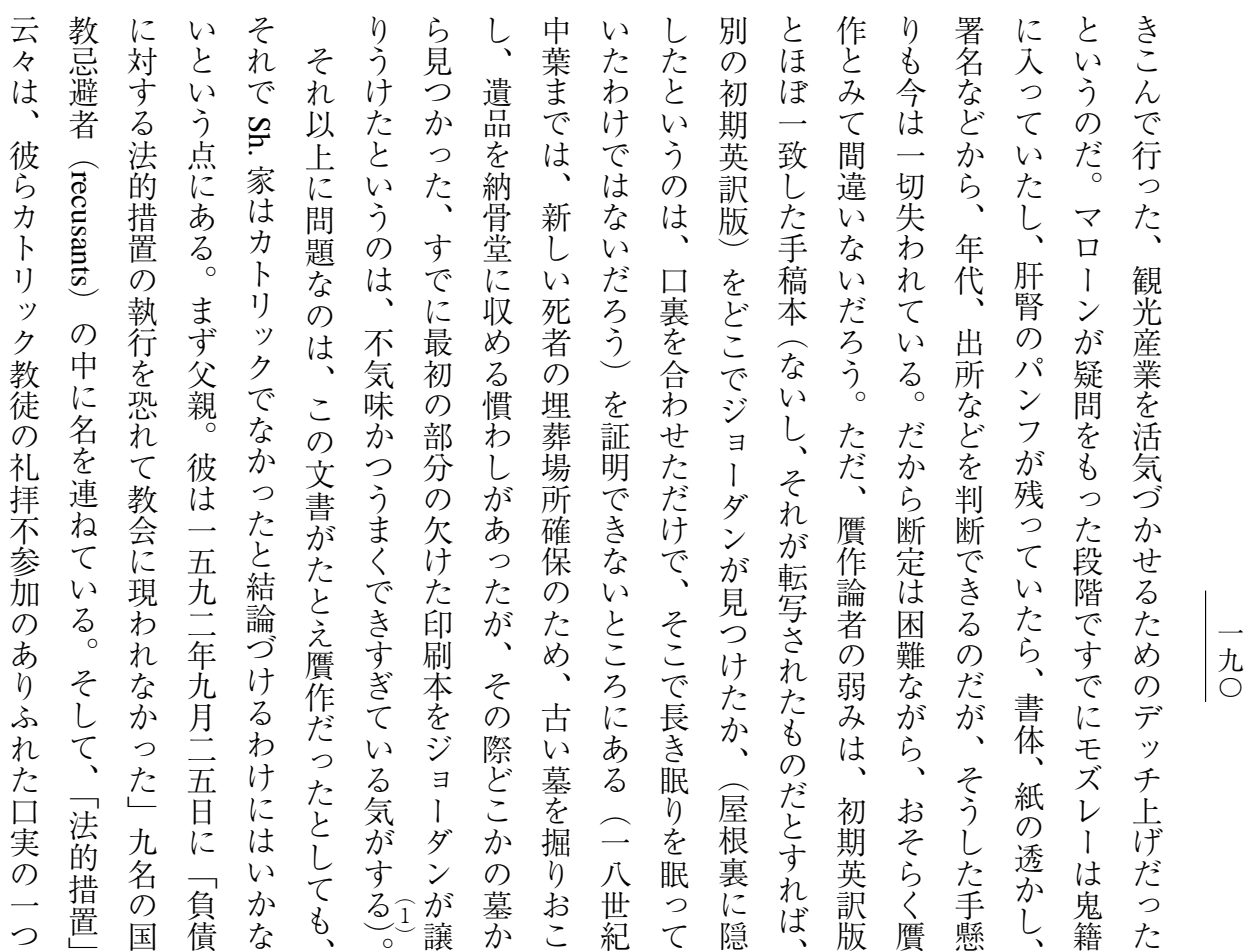




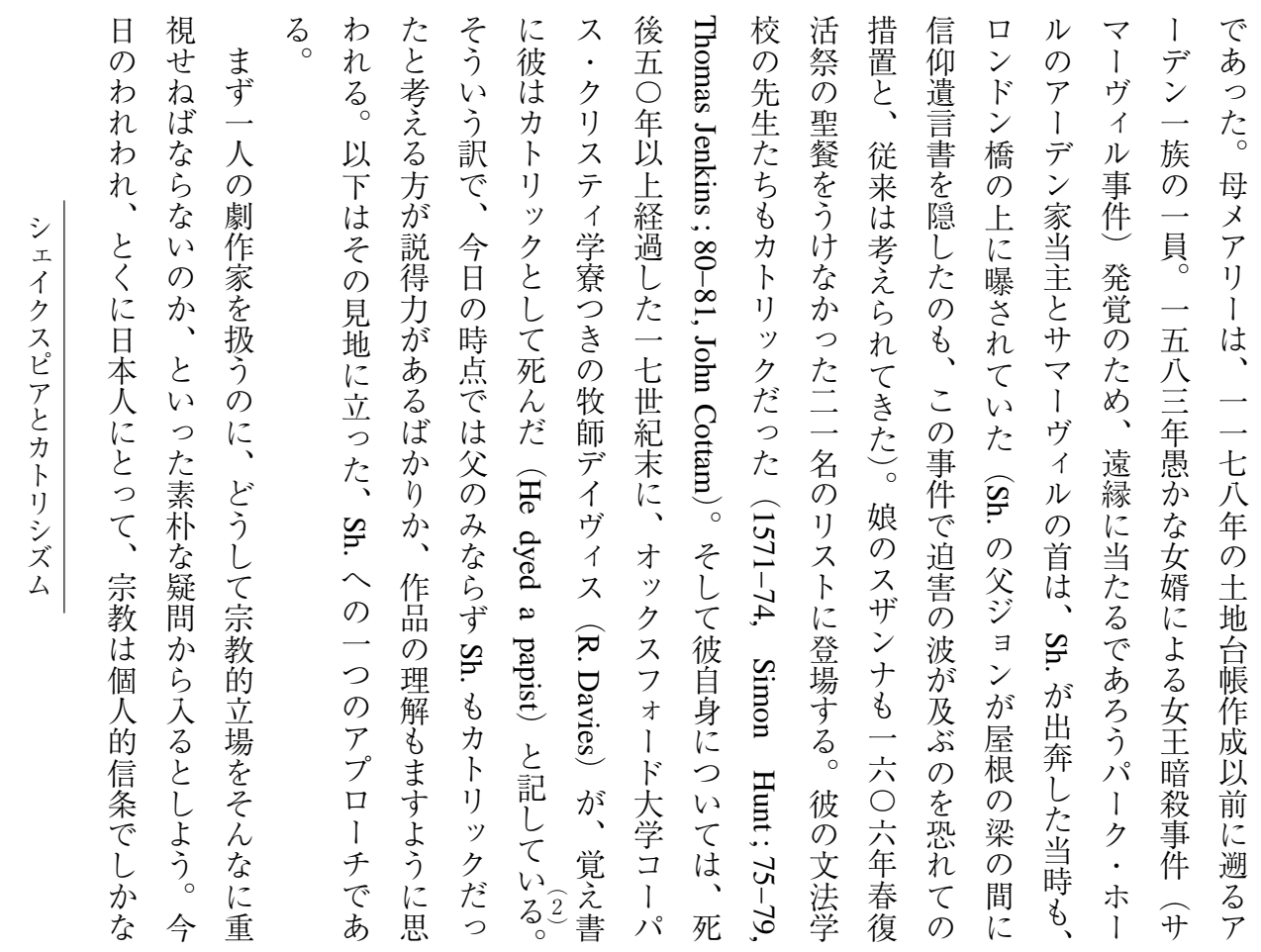

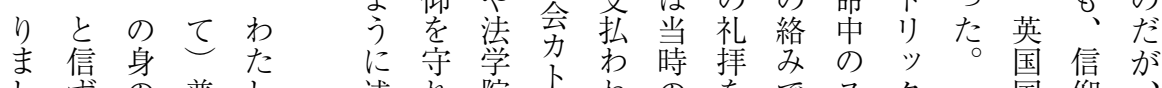

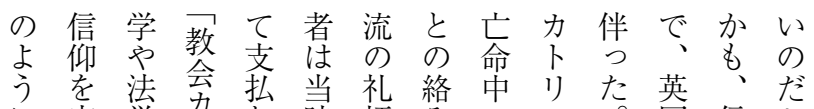

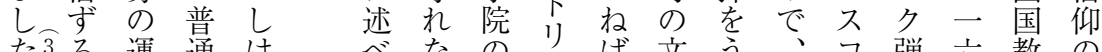

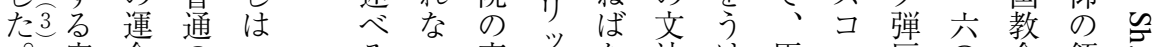
家 命 $の$ 規

出扮模 外

あ゙い市て れ

り热系奆

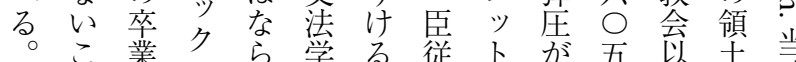

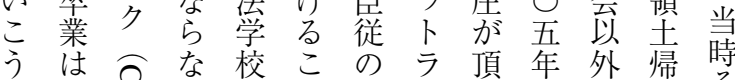

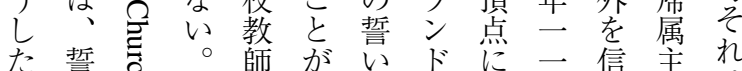

まれぼきき

事い乞そ公穴達月奉義は

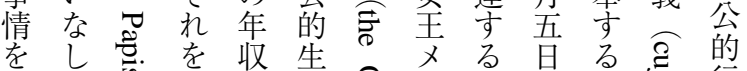

故 どロ の

$つ$ 辛 マ 数

ね 酸のに

\begin{tabular}{l|llll} 
& に & 教 & 枝 \\
九 & 殉 & 嘗 & え & 分 \\
教 & め & に & か
\end{tabular}

、に恐に活 き

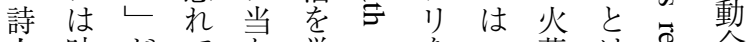

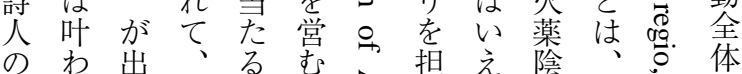

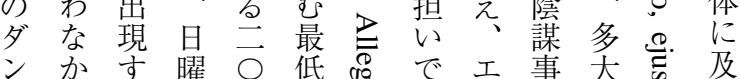

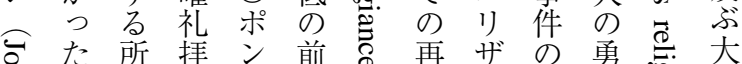

真例従れ

剣はたた

に見ば場

考つか合

えかりは

まるに別

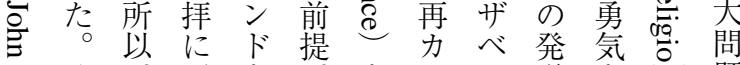

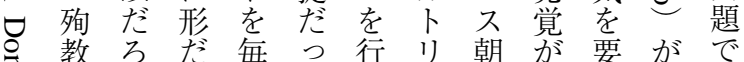

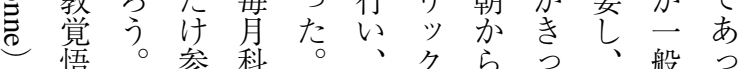

は㔯勿列料不国化す か犠的た

以少論する と履教計でけ牲な 画に 


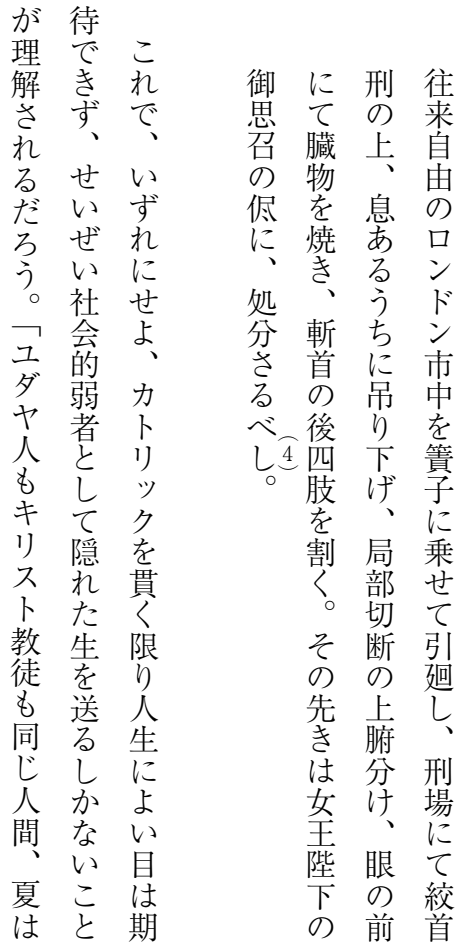

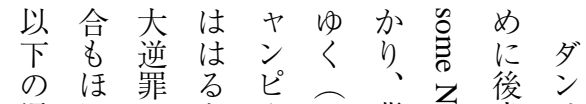

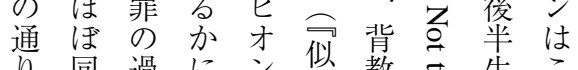

り同過に シ 酷厄 而者 る 生 こ

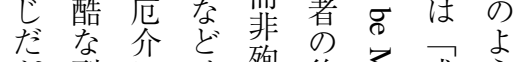

が藅なには教後学或う

今㤎る 己者め 方者息

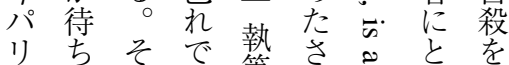

1構れは筆を劣う真紀

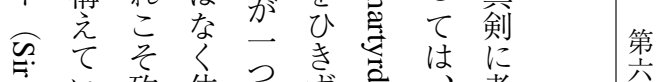

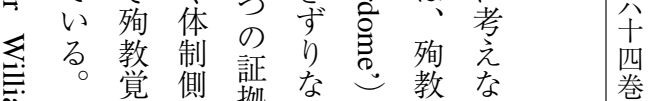

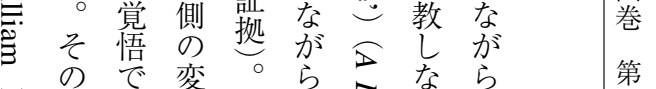

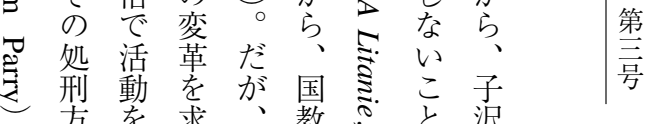

の法行め同会 $メ$ が 山

例はいるる

あすれ゙捕ら、人りるき

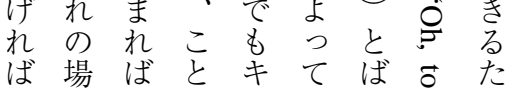

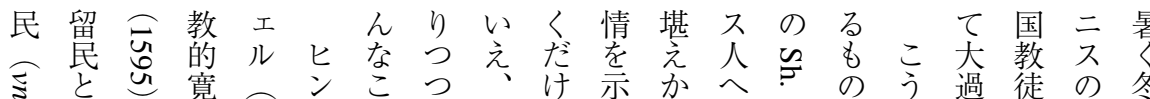

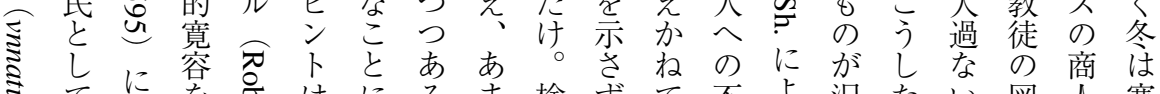
ミて筧求名はにるま検ずて不よ沢たい罒人寒

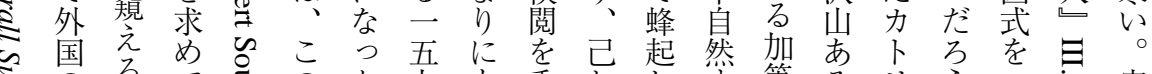

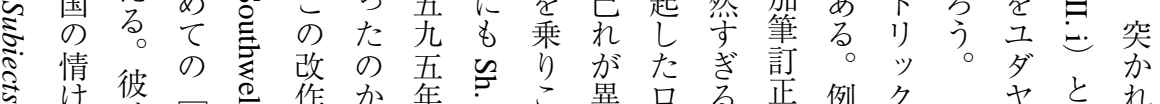

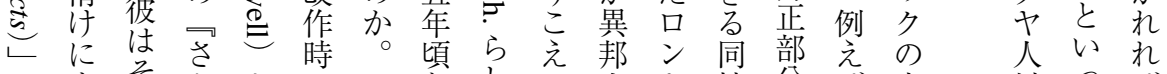

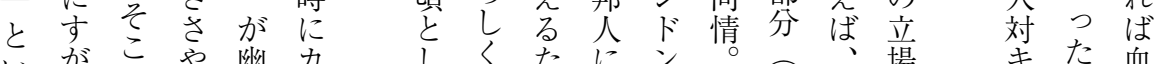

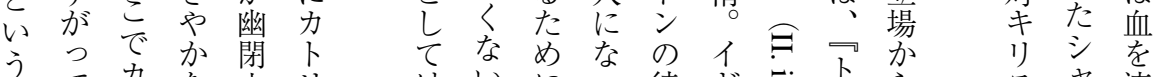

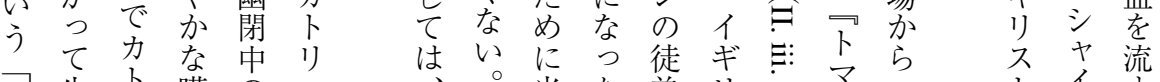

卑生卢嘆の

賤きり 願ロロ ク

な大 人 引

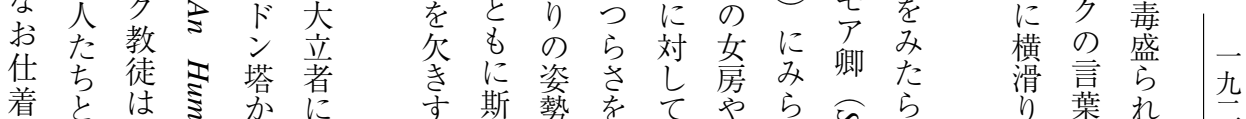

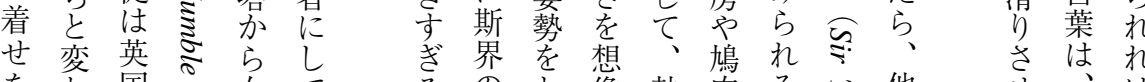

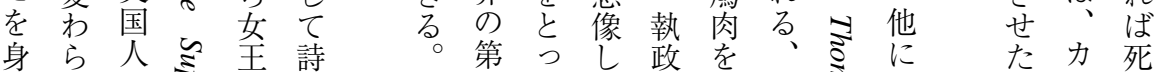

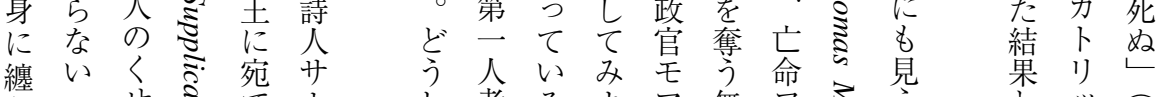

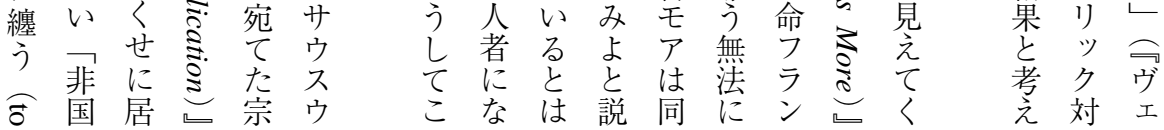




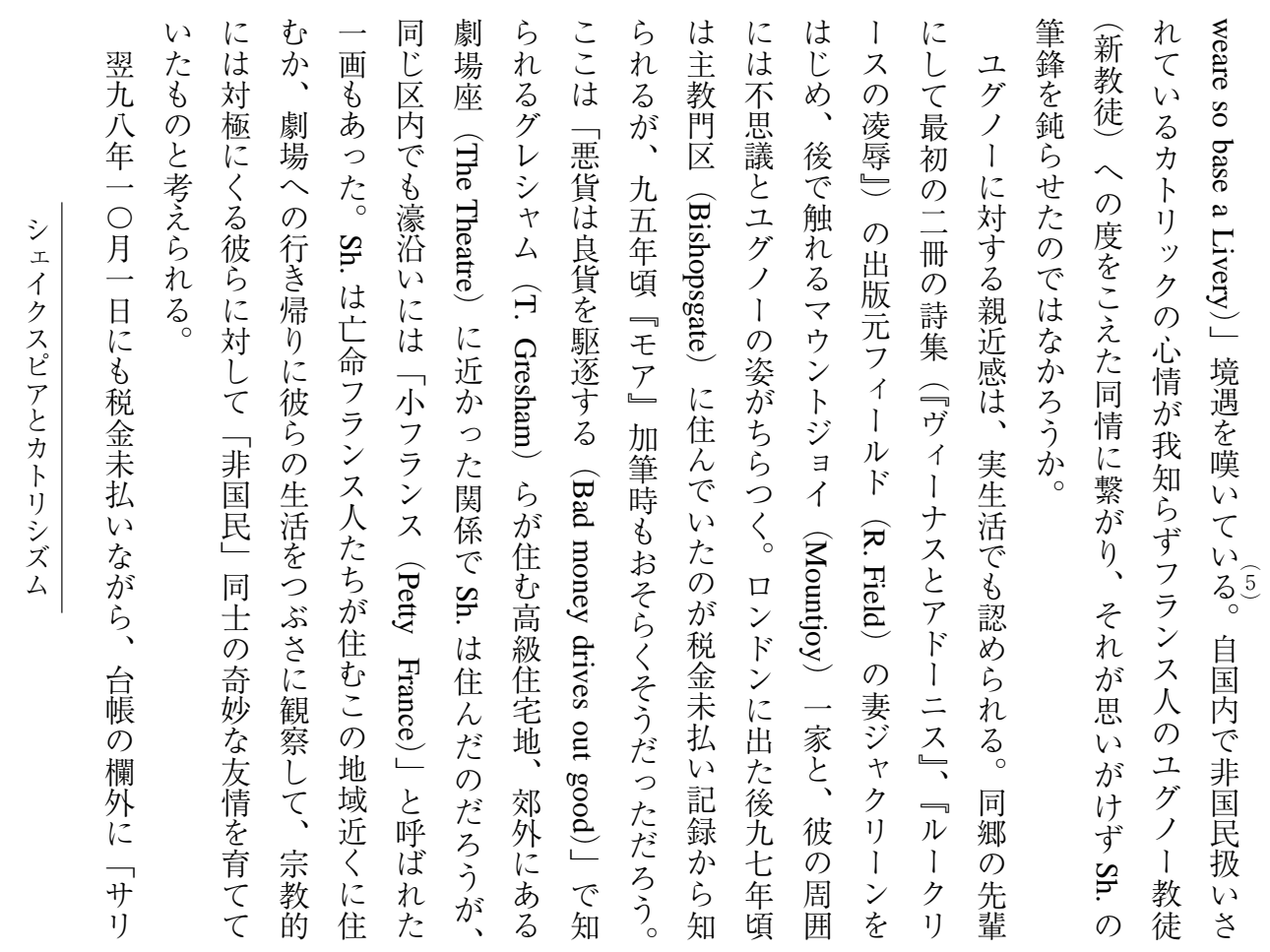

忘る録産すグロト最の二ドえ彼度名、っ、

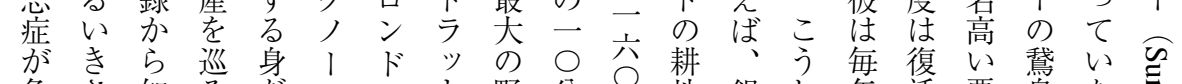

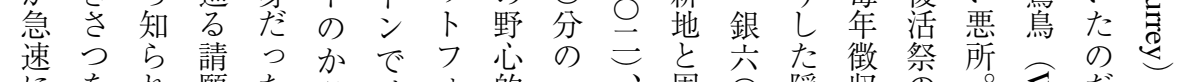

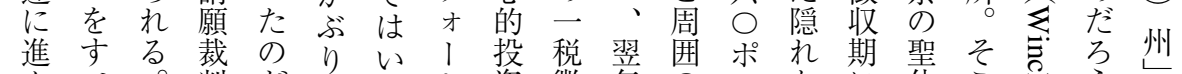

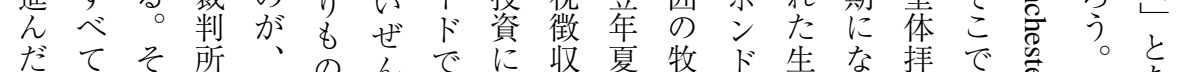

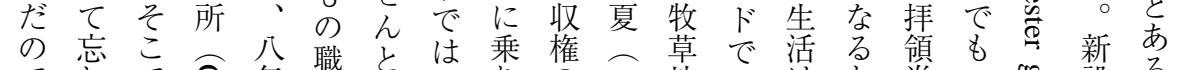

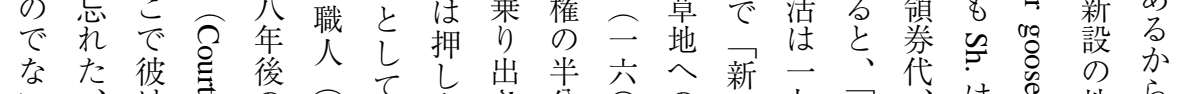

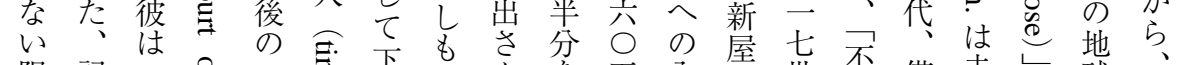

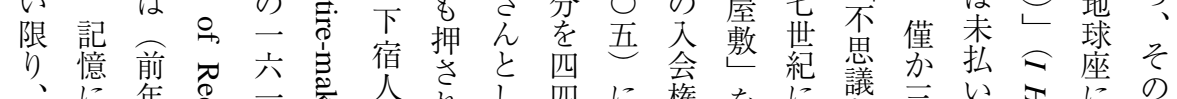

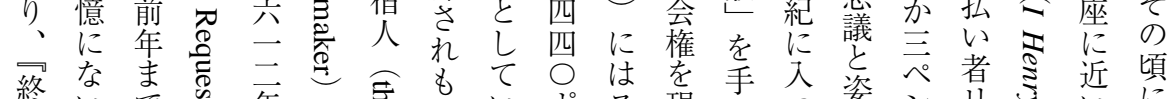

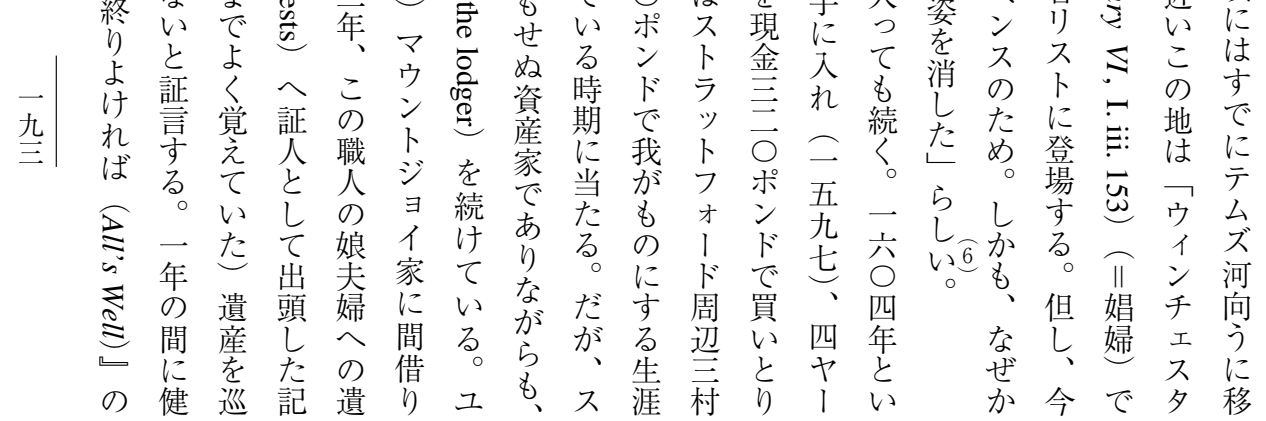




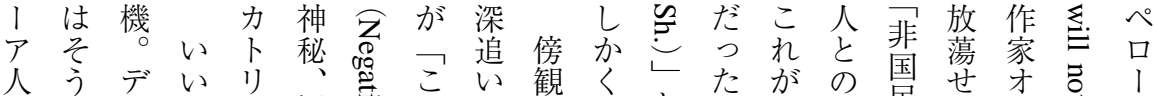

くな ズ 例 ツ

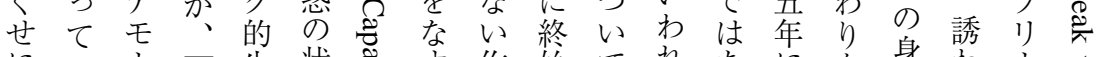

に腕 る

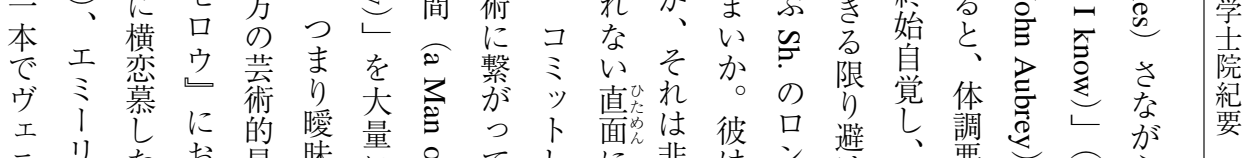

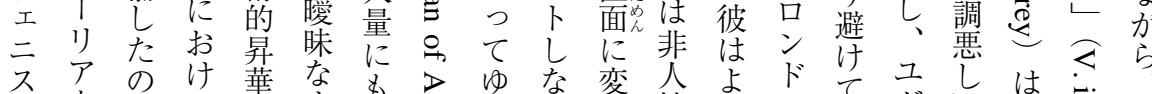

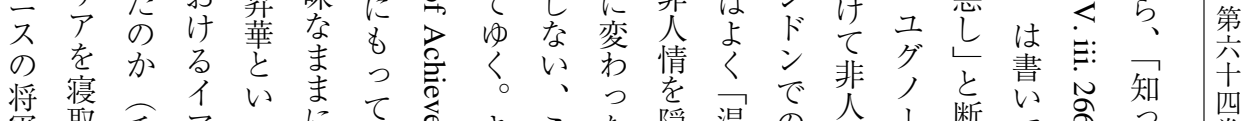

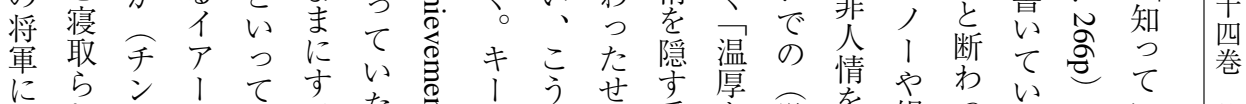

ま゙れた テ

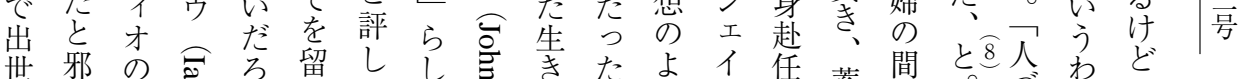

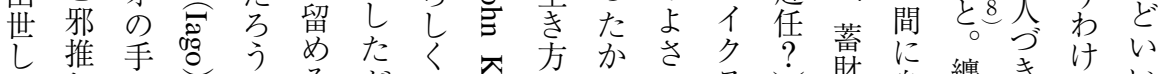

た推 手ささう め た

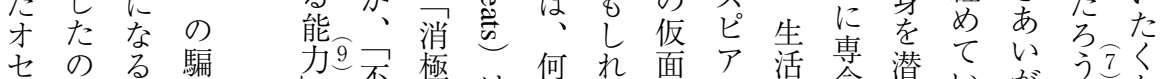

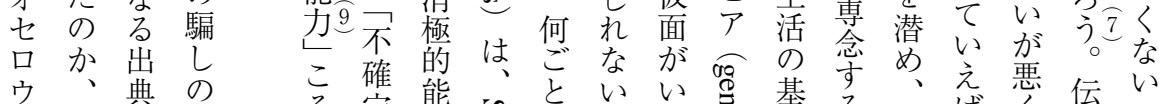

がム 典 の 動 そ 定熊

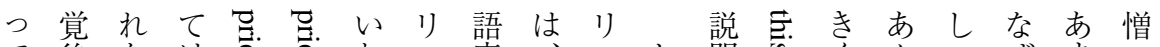

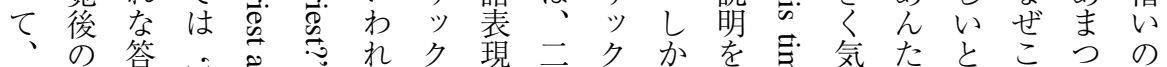

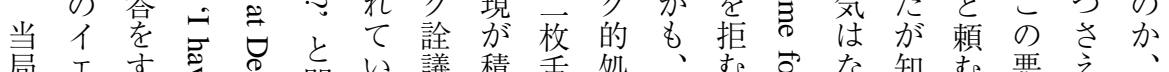
局エ 方 六

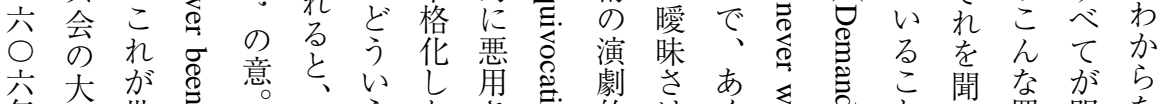

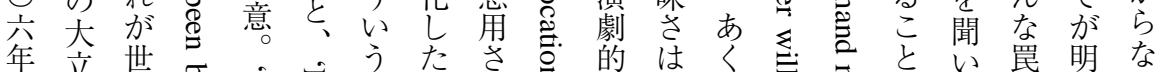

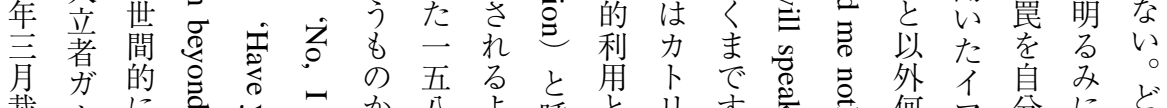
裁

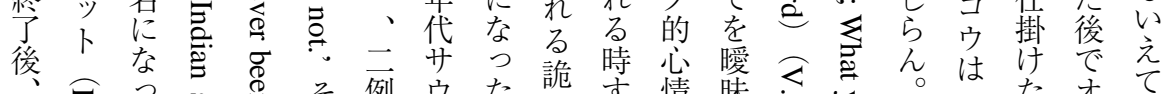

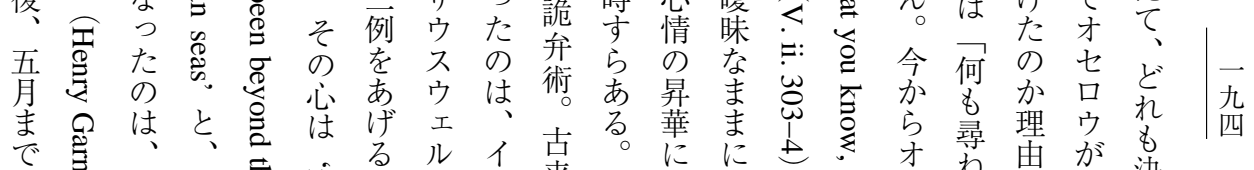

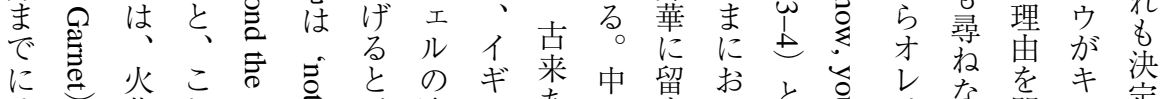
その薬杂怘 模 詮 謀 た

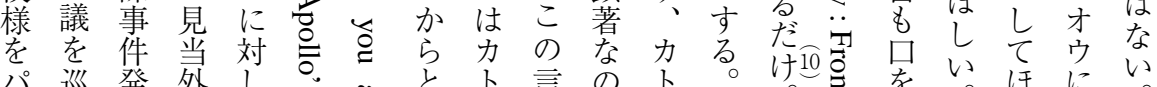




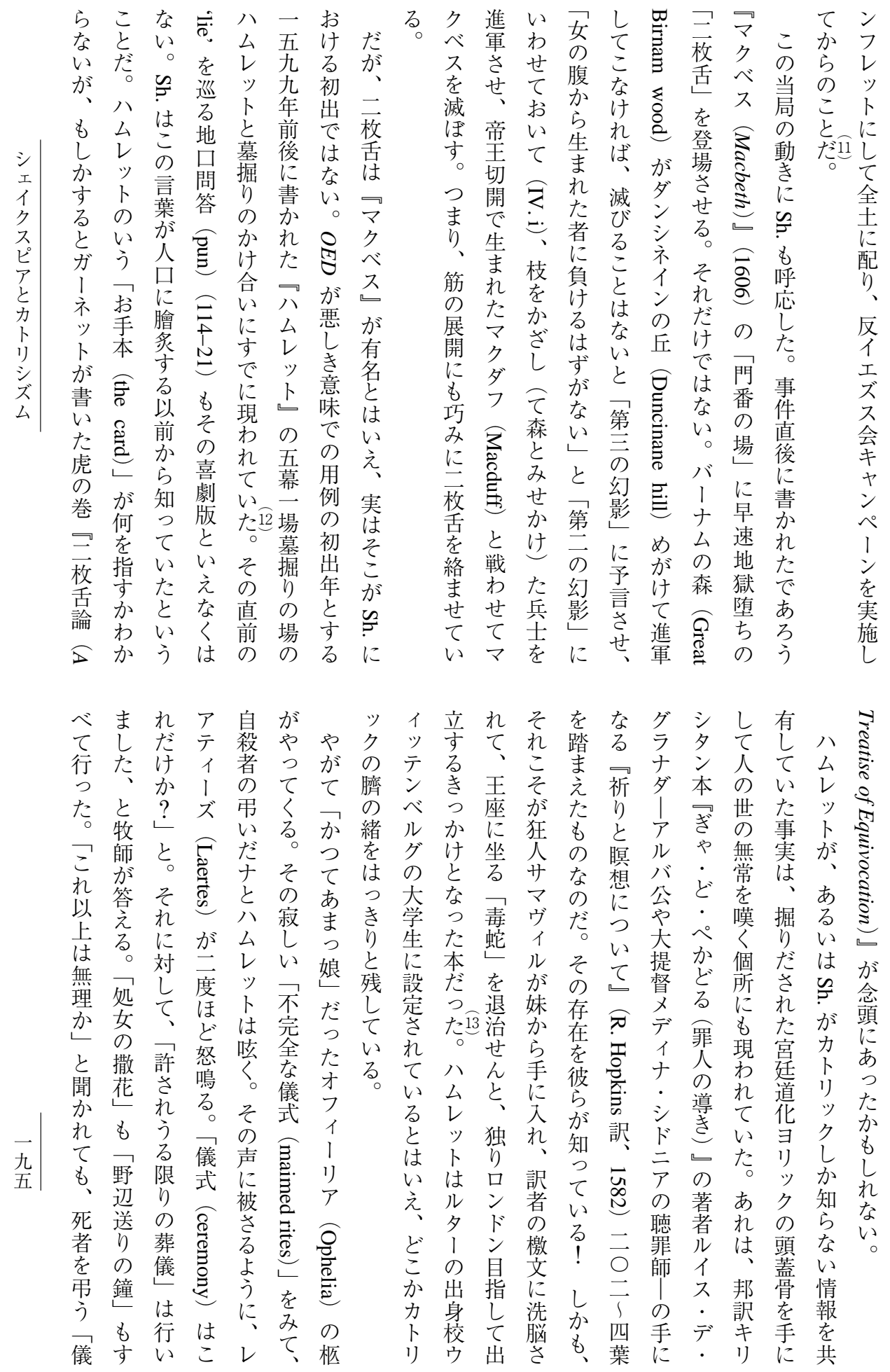




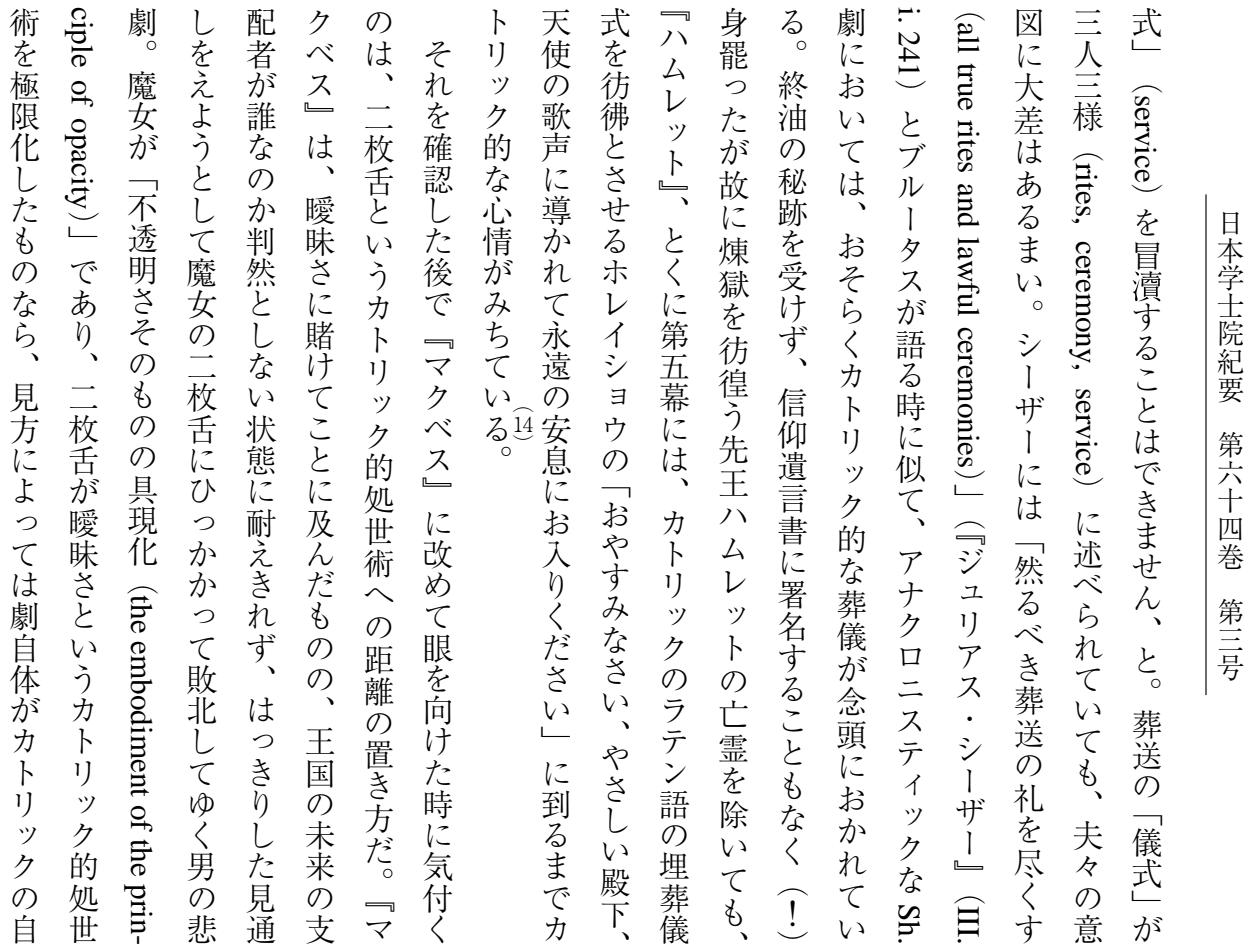

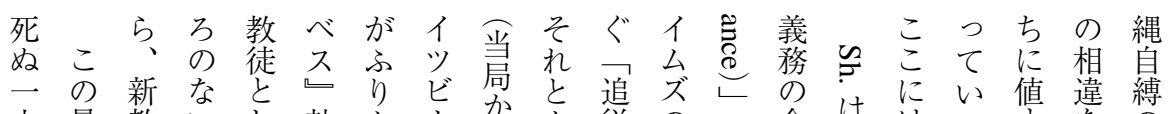

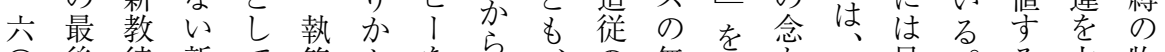

後 徒 新て 筆 かをを文、の 無執が見。る 力物

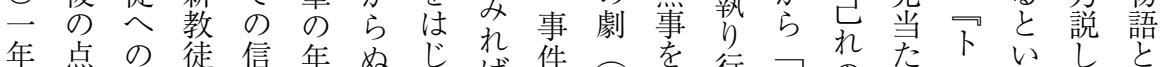

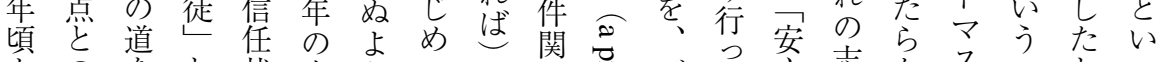

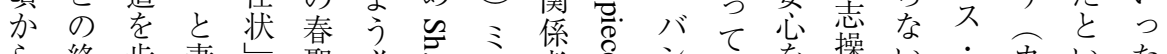

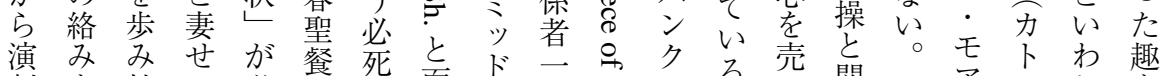

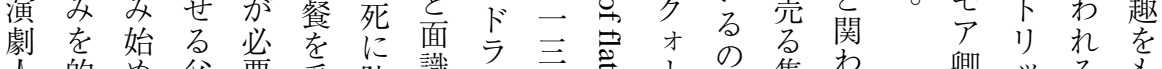

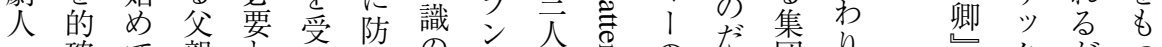

き確て 親と察な

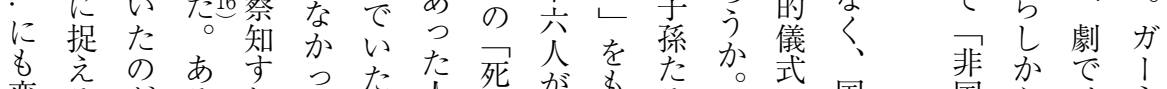

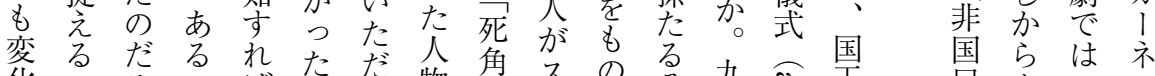

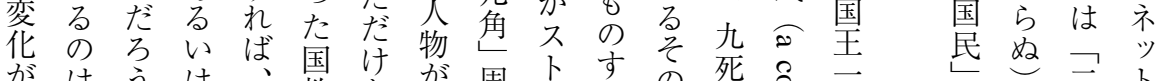

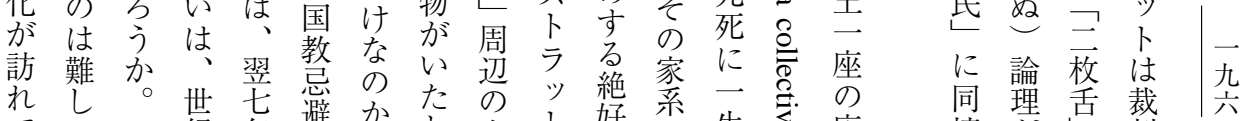

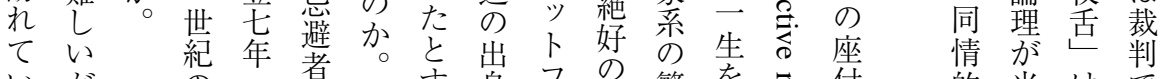

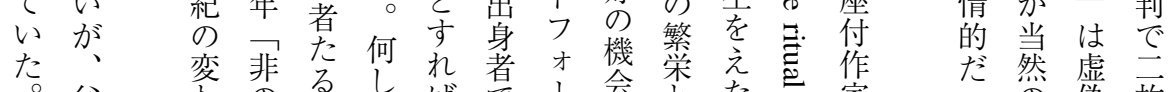

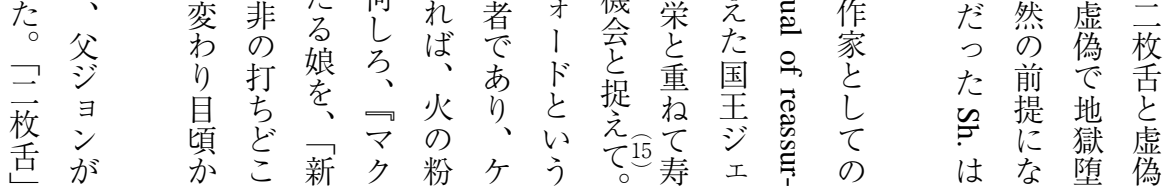




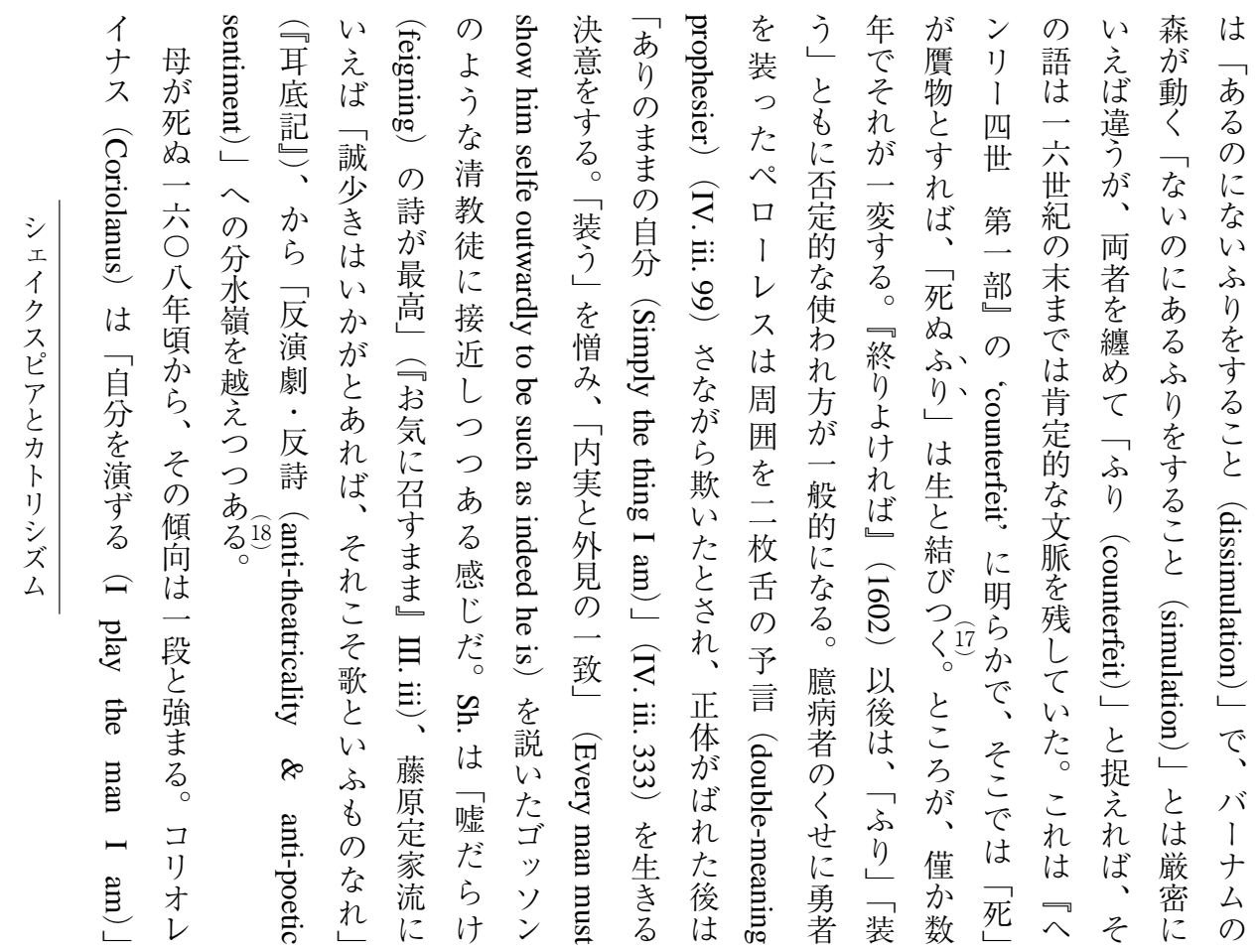

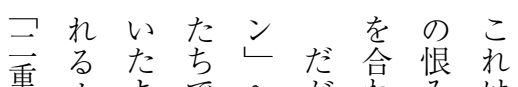

重力よ でへがわ噫力致そであ

意識々う訪の、せを命れも皇

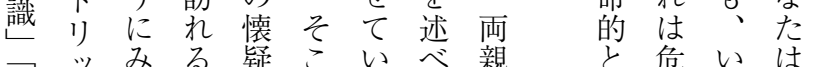

消ク ク え

極的て、問 き

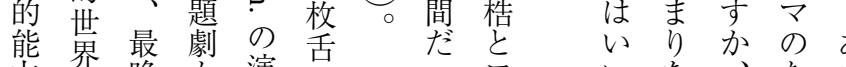

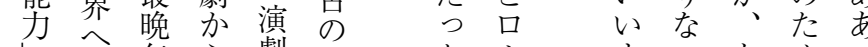

の 再 年 ら

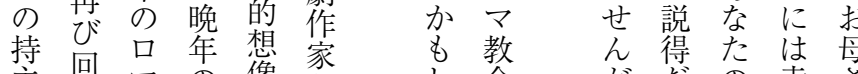

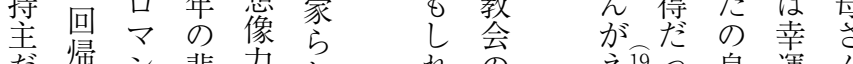

た帰ン悲力し れ

って ス 劇 が劇页い な そ

た ゆ 劇 で 頂と新 点 こ

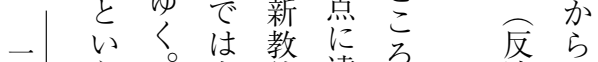

九 う 要 奇徒達 だ演解

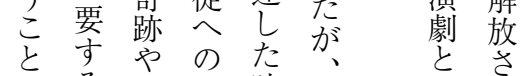

だる 神道時、文视

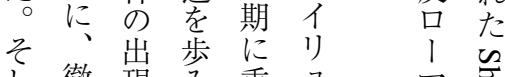

し徹現み重工文高

て 頭が始な ! は が

$\begin{array}{llllll}\text { 見尾 徹 み } & \text { ๖ } & \text { か } & \text { か } & \text { 歩 } & \text { 積 } \\ & & \text { 調 } & \text { 年 }\end{array}$

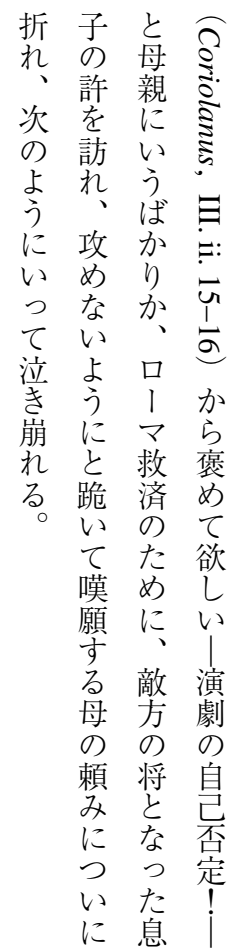




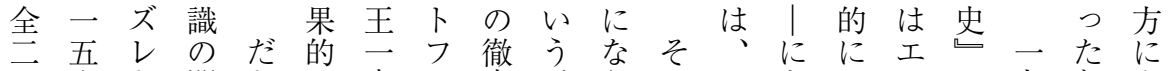

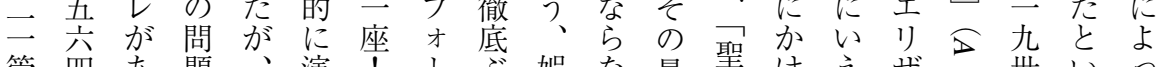

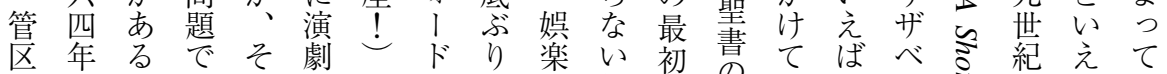

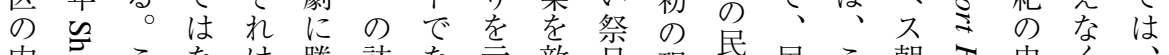
内 こなは勝訪な示敵尔現民民こ朝志史々

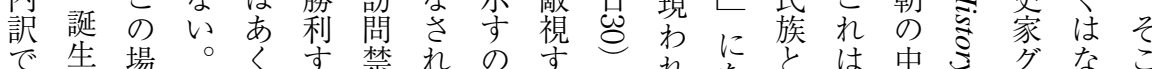

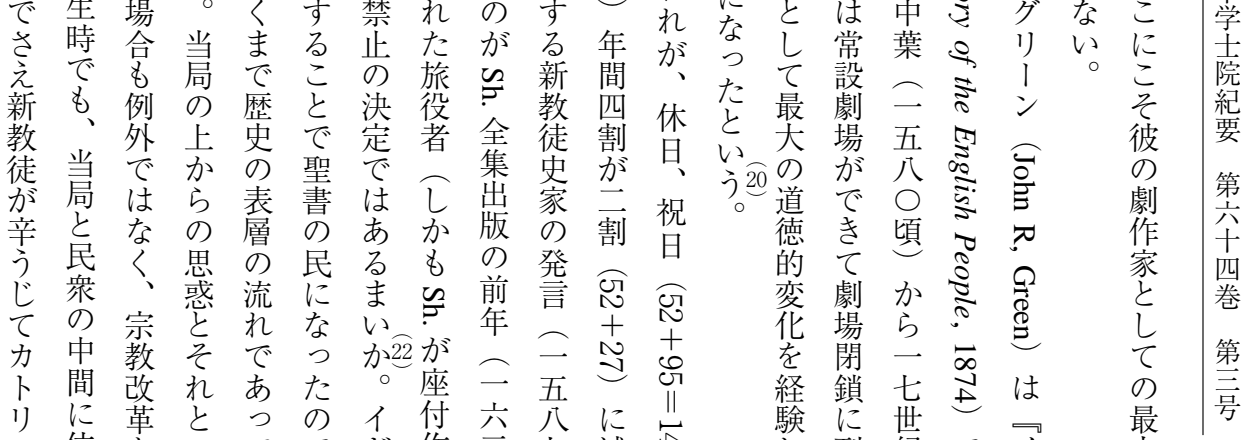

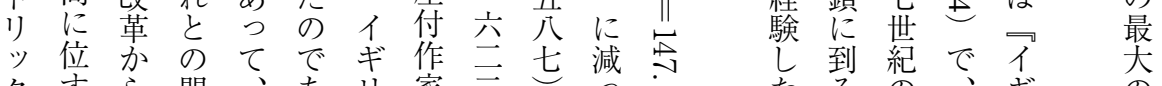

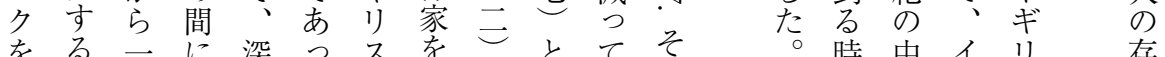

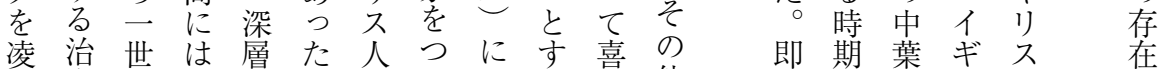

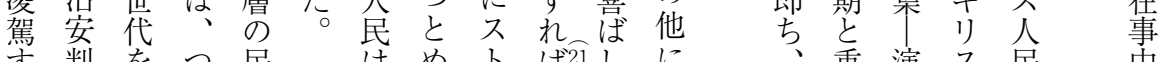

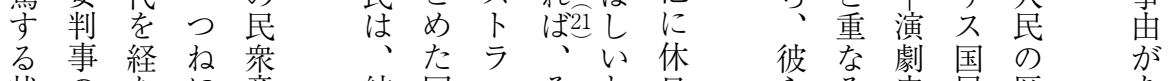
状のたに意結国ッそと百ら哽民歴市

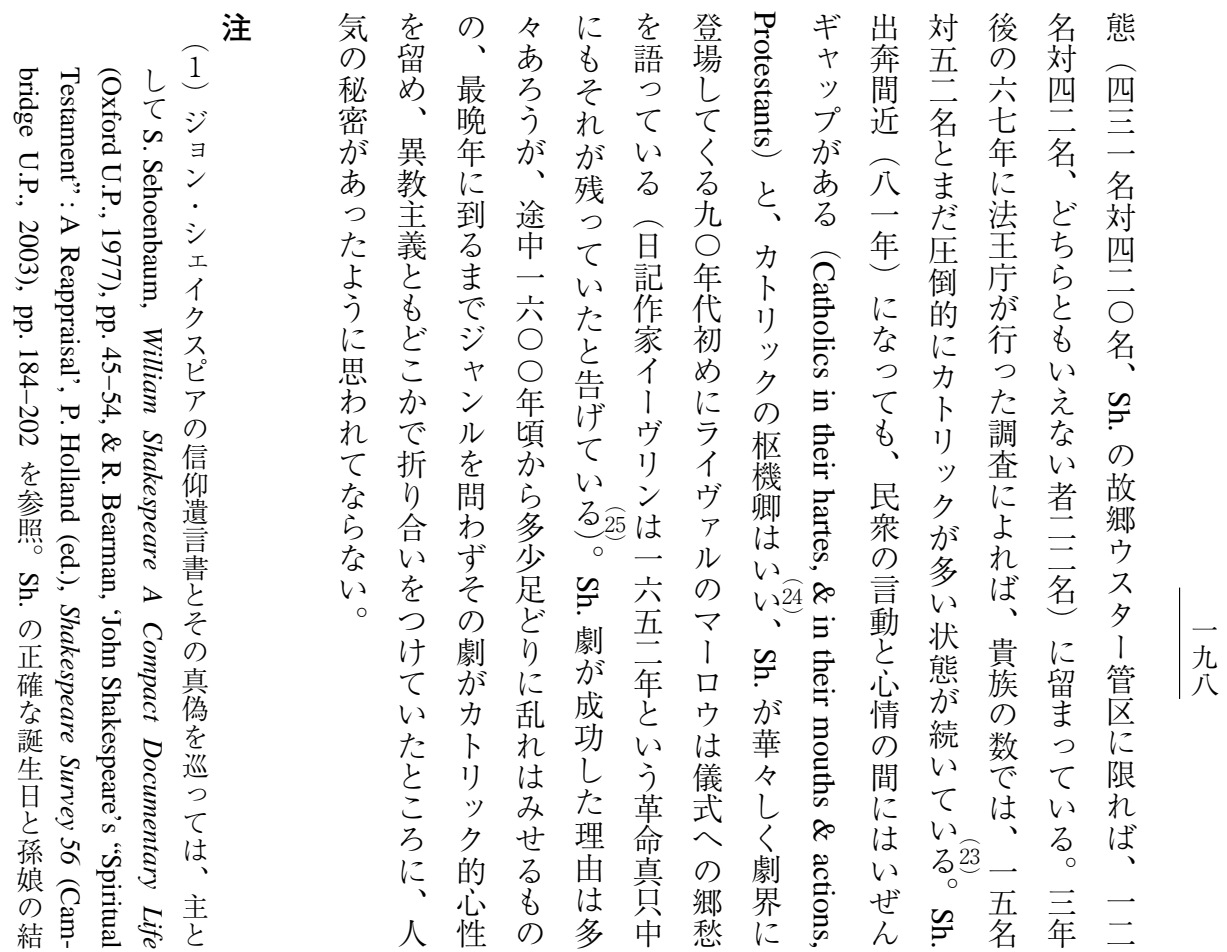




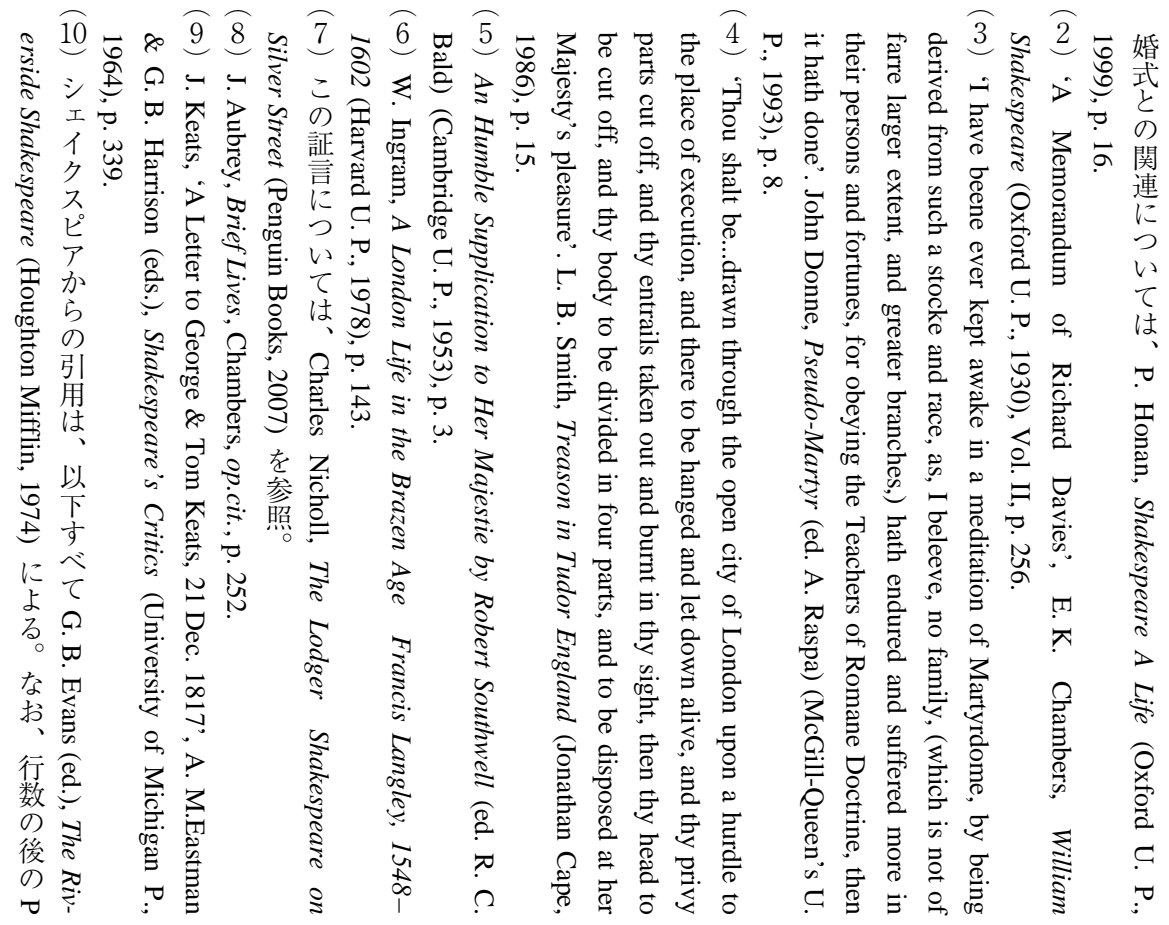

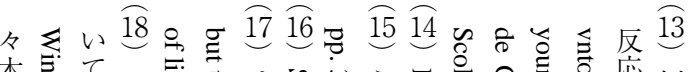

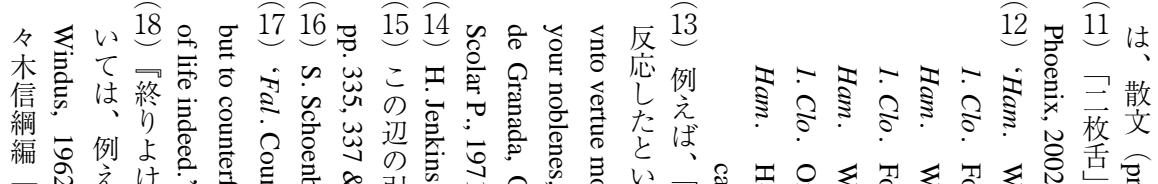

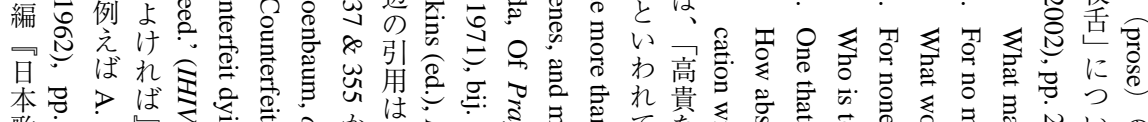

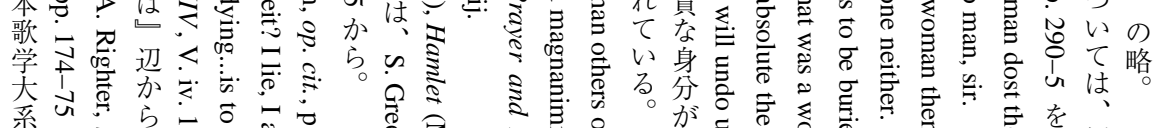

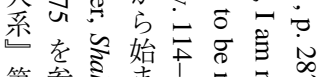

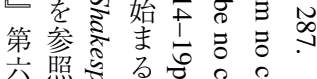

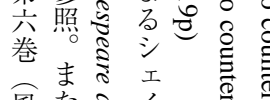

風たミイ

書军学

产.

房底衤

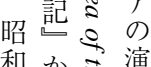

和 か演

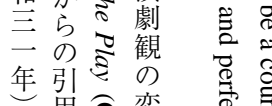

一 は色遷

八公遷

Ð

高 है.

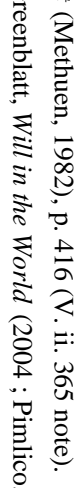

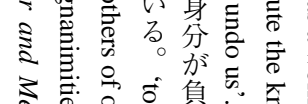

ఏ.

一佐

害

今.

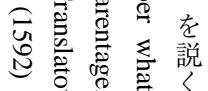

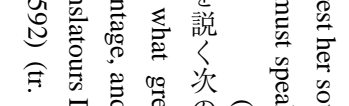

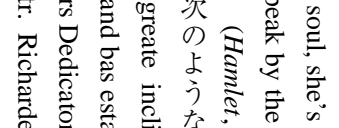

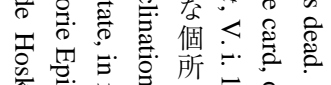

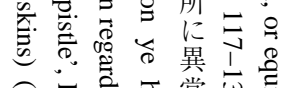

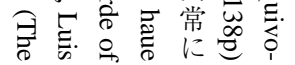

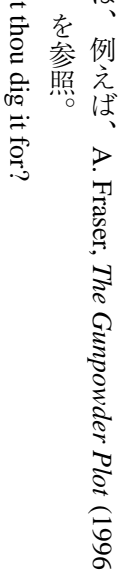




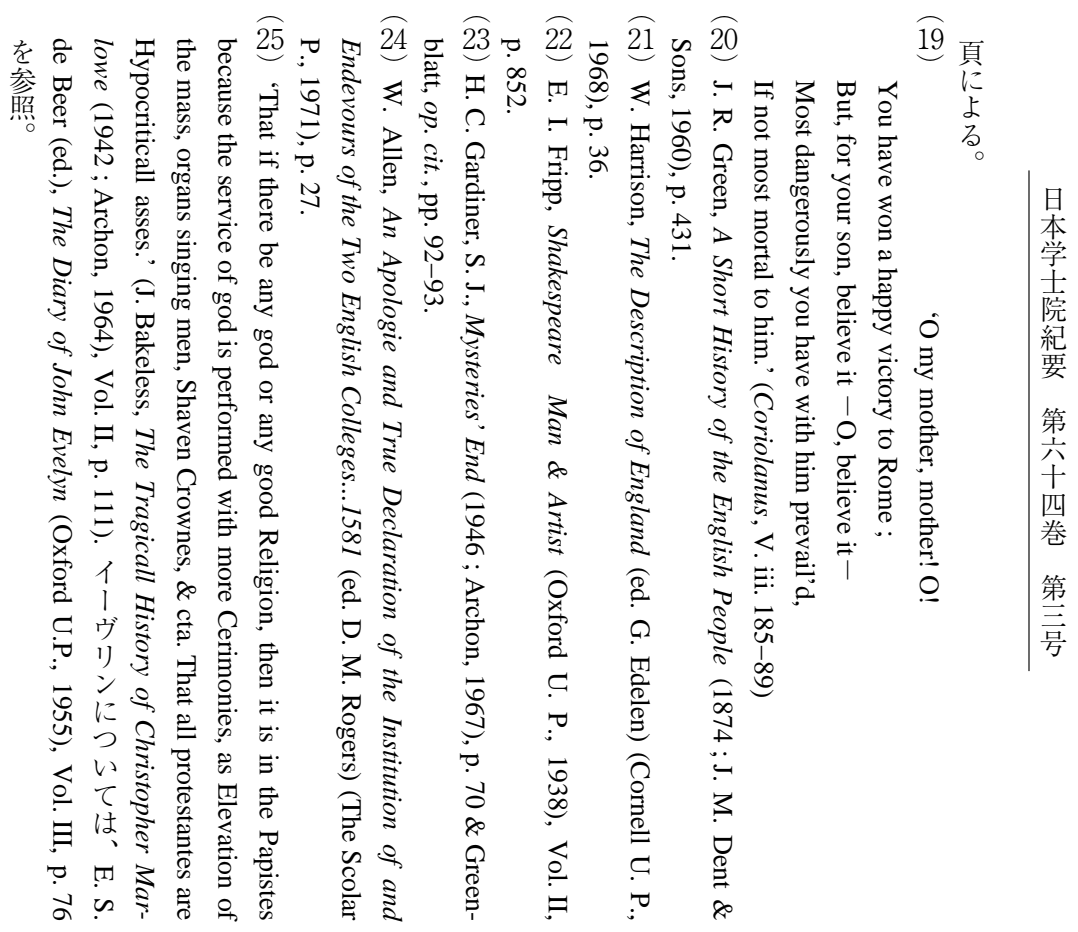

$\mid \begin{aligned} & \text { 三 } \\ & 0 \\ & 0\end{aligned}$ 
Protestantism, he once again comes back in the last phase of his dramatic career to the world where miracles and theophany take place. Catholicism remained ineffaceably at the core of his mentality throughout his life. This is why Shakespearean drama was so popular among people who were 'Catholics in their hartes, \& in their mouths \& actions, Protestants'. 
Moor? All can be possible, but nothing is certain. Moreover, when asked the reason of his ensnarement, Iago leaves everything ambiguous by just saying, 'Demand me nothing... From this time forth I never will speak word' ( V . ii. 3034).

Shakespeare also made dramatic use of Catholic way of living. The typical example is the sophistry called equivocation which means ambiguous usage of words, and it is this means of evasion that Catholics resorted to in their trials for self-protection. It became well-known to ordinary people through the trial of Henry Garnet, S.J., after the Gunpowder Plot in 1605.

Soon after the trial Shakespeare made full use of this rhetoric in Macbeth (1606), and represented the titular hero who was defeated by 'th' equivocation of the fiend That lies like truth' (V. v. 43-44). But we feel it strange about this play that, quite contrary to Hamlet, written a few years before with warm feelings toward Catholicism, here is hardly any sympathy to this Catholic discourse of opacity. Something seems to have happened around 1601, when Shakespeare's father died. Words like 'counterfeit' and 'feigning', too, which had retained the positive context before the turn of the century, began to be used solely in their negative senses thereafter. Shakespeare is passing over the watershed and rapidly coming near Puritan critics of anti-theatricality who advocated, 'Every man must show him selfe outwardly to be such as indeed he is.'

Such inclination became stronger in him around 1608, when his mother died. Coriolanus who told in full pride, 'I play The man I am' (III. ii. 15-16) - selfdenial of the idea of the play itself! - , gave in to his mother's supplication not to attack Rome, thus crying :

You have won a happy victory to Rome ;

But, for your son, belive it $-\mathrm{O}$, belive it -

Most dangerously you have with him prevail'd.

(Coriolanus, V. iii. 186-88)

This may be the moment that Shakespeare at last expressed his long-harboured resentment against his parents and Roman Catholicism.

What is interesting about this master of double consciousness is that appearance of his doubts about the power of illusion coincides with the period when his poetic imagination was strongest, and that, in spite of his growing sympathy for 
In the present-day Japan religion is merely a matter of one's private morality, but quite different was the case with Shakespeare's England, where the whole structure of one's public action was controlled by it. Catholics who would not take the Oath of Allegiance were barred from proceeding to a degree at the Universities or following studies in the Inns of Court. If they did not want to pay fines, they were obliged to conform outwardly to the Anglican Church and attend the services as 'Church Papists.' To remain a Catholic in the Elizabethan England meant to live a life of the socially weak.

There are many scenes in Shakespeare's plays which, if we regard him as a Catholic, can easily be understood. For instance, More's attitude toward the outrage of French Huguenot exiles in London in Sir Thomas More. Thomas More, Sheriff of London, is too generous to those 'Lombard' exiles who want to 'purchase' honest English wives and 'possess' pigeon's meat free of charge from English labourers. His unnaturally deep sympathy with them could be beyond our comprehension unless we think it has something to do with the author's feelings as an English Catholic ; English Catholics, much like French exiles in England, were reckoned as 'unnaturall Subjects' in their own country.

This 'so base a livery' as unnatural subjects he continued to wear throughout his London life. As John Aubrey, a biographer, tells us, 'he was not a company keeper', living among exiles and harlots, paying no taxes, and devoting himself to saving money. Even when he appeared in the Court of Requests as a witness to a case of inheritance of a Huguenot family, he claimed he did not remember the details, thus refusing to involve himself in the trouble. He was just following the example of Parolles : 'I will not speak what I know' ( $A W W, \mathrm{~V}$. iii. 266p). He has often been called 'gentle' Shakespeare, but that may be the epithet for a great bystander whose amiableness is his heartlessness-hiding mask turned real face.

Gentle Shakespeare as a bystander finds a reflection in his dramaturgy. 'Negative Capability' John Keats found in Shakespeare, a capability 'of being in uncertainties $\cdots$ without any irritable reaching after fact and reason', is nothing else than the artistic sublimation of this mentality. To give an example, motives of Iago's tricking of Othello into killing Desdemona. Does Iago feel illicit love for Desdemona? Does he suspect his wife has slept with Othello? Or, is he envious of Othello who has been promoted to the Generalship of Venice, even though he is a 


\title{
Shakespeare and Catholicism
}

\author{
Yasuo TAMAIZUMI, M. J. A.
}

In April 1757, the then owner of Shakespeare's birthplace, Thomas Hart, fifth lineal descendant of the poet's sister Joan, was employing labourers to retile his roof, when a booklet consisting of six leaves was allegedly found, between the rafters and a tiling, by Joseph Mosley, a master bricklayer. This pamphlet, which has come to be known as The Spiritual Last Will and Testament of the poet's father, John Shakespeare, is a Catholic profession of faith in fourteen articles. Regretably, its existence was last heard of in 1790 , so we now have no means to check its authenticity. But it is generally thought to be a forgery, committed, with the help of Mosley, by John Jordan, a Stratford wheelwright and an antiquarian, who first copied the manuscript in 1785, some thirty years after its discovery. As a guide for naive visitors in and around Shakespeare's town, Jordan seems to have hit upon the idea of forging the document to promote the so-called 'Shakespeare Industry' and make more money.

But if this document was a forgery, it does not necessarily follow that Shakespeare was not a Catholic. His father was one of those who were absent from church in 1592 'for fear of processes', which was the common excuse Catholic recusants used for not attending church. His mother, Mary, comes of the Arden family, one of Warwickshire's most distinguished Catholic families, and John Somerville, a would-be assassin of Queen Elizabeth in 1583, was a son-in-law of another Arden family. When Shakespeare first crossed the London Bridge in the late 1580s, John's head was still exposed to the view of visitors on the bridge. Teachers in his grammar school days were also Catholics. Richard Davies, a chaplain of Corpus Christi College, Oxford in the late seventeenth century, wrote a memorandum on Shakespeare : 'He died a papist.' The following is the summary of an approach to Shakespeare and his work from the standpoint of Shakespeare as a crypt-Catholic. 